\title{
THE VALIDATION OF THE TRANSFORMATION BETWEEN AN OLD GEODETIC REFERENCE FRAME AND A MODERN REFERENCE FRAME, BY USING EXTERNAL SPACE TECHNIQUES SITES: THE CASE STUDY OF THE HELLENIC GEODETIC REFERENCE SYSTEM OF 1987
}

\author{
Validação da transformação entre sistemas de referência antigos e modernos \\ com uso de estações de referência externas: caso de estudo do Sistema Geodésico \\ de Referência Helênico de 1987
}

\author{
loannis D. Doukas ${ }^{1}$ \\ Dimitrios Ampatzidis ${ }^{2}$ \\ Vassileios Kampouris ${ }^{1}$
}

1 Aristotle University of Thessaloniki, Department of Geothechnical Works, Laboratory of Geomatics, University Campus, 54024, Thessaloniki, Greece. Email: jdoukas@civil.auth.gr; vkampour@gmail.com.

2 Federal Agency of Cartography and Geodesy (BKG), Richard-Strauss-Allee 11, 60598, Frankfurt a.M., Germany.Email: dimitrios.ampatzidis@bkg.bund.de

\begin{abstract}
Many of the old geodetic reference frames which realized in the previous decades using classical observations carry biases. These biases are mainly caused due to the problematic observations and/or the tectonic motion. That is the case of the official Greek geodetic reference frame which consists of classical and satellite observations. Herein, we present a rigorous approach of the reconstruction of the Greek official reference frame based on the modern geodetic reference frames and their ability to express the spatial position and the dynamic change of the stations. We applied the rigorous approach to ninety stations located in Greece and we compare it with the officially accepted procedure. We found a consistency at $59.4 \mathrm{~cm}$ between the rigorous and the officially accepted approaches, respectively. The associated mean bias estimation was estimated at $51.4 \mathrm{~cm}$, indicating the resistance of a rather large amount of systematic effects. In addition, the observed discrepancies between the two approaches show great inhomogeneity all over the country.
\end{abstract}

Keywords: Geodetic Reference System (GRS), GRS Datum, transformation between two GRS, ETRS89

Resumo: Muitos dos antigos sistemas geodésicos de referência que foram realizados nas últimas décadas por meio de observações clássicas apresentam erros. Estes erros são principalmente oriundos de problemas nas observações e/ou movimentos tectônicos. Este é o caso do sistema geodésico de referência Grego, que consiste de observações clássicas e por satélites. Neste trabalho apresenta-se uma abordagem rigorosa para a reconstrução deste sistema geodésico de referência baseada nos sistemas de referência modernos e na sua habilidade de expressar a posição espacial 
e as mudanças dinâmicas das estações de referência. Foi aplicada a abordagem rigorosa a noventa estações localizadas na Grécia e foi realizada uma comparação com o procedimento oficialmente aceito. Encontrou-se uma consistência de 59,4 cm entre os procedimentos rigoroso e oficial. A estimativa de erro associada foi de $51,4 \mathrm{~cm}$, indicando grande efeito sistemático. Além disso, as discrepâncias observadas entre as duas abordagens demonstram falta de homogeneidade ao longo do país.

Palavras-chave: Datum Clássico; Transformação; Campo de velocidade; ETRS89; Sistema de referência.

\section{Introduction}

Classical geodetic reference frames were mainly realized with classical measurements which have been carried out in the preceding decades. The rapid development of space techniques and their implementation to Geodesy and Surveying led to significant improvement of the 4D positioning. In Greece, the official geodetic reference system, called the 'Hellenic Geodetic Reference System of 1987-HGRS1987' (Hellenic Mapping and Cadastral Organization 1987, Takos 1989, Veis 1996), was mainly realized by classical measurements (angles, azimuths and distances), where the involved mentioned measurements can exceed 50 years in age. HGRS1987 specifies a nongeocentric datum that is tied to the coordinates of the key geodetic station at the Dionysos Satellite Observatory (DSO) northeast of Athens. In addition, data from TRANSIT (Doppler) and GPS observations were assimilated in thirty (30) carefully selected stations. The initial uncertainty was estimated as $0.1 \mathrm{ppm}$ (Hellenic Mapping and Cadastral Organization 1987).

By taking into consideration both: (a) the age of the measurements and (b) the geophysical behavior of the area, we can imply that is rather possible for HGRS1987 to carry significant systematic effects (see also: Rokos et al. 2010). In addition, we should underline that the HGRS1987 was not adjusted uniformly. The term 'uniformly' reflects the fact that the Greek triangulation network was adjusted in groups per region, not simultaneously (Takos 1989). Hence, it is quite possible that this feature could influence the quality of the reference frame. For example, the non-uniformly adjusted network could induce severe inconsistencies regarding the scale and the orientation (see e.g. Katsambalos and Kotsakis 2010, Chatzinikos and Kotsakis 2016).

In 2009, a transformation model between the European Terrestrial Reference System of 1989 (ETRS89) and HGRS1987 was officially released, performing 8.3cm RMS nationwide (Katsambalos et al. 2010). The aforementioned precision was obtained by gridding the residuals which were estimated after the 3D-Helmert transformation of $~ 2,200$ stations between ITRF2000 and HGRS1987.

We should point out that HGRS1987 is realized from the reference frame of BTS87 (predecessor of International Terrestrial Reference System-ITRS) by 3D-shifting the BTS87-wise coordinates. These 3D-shifts practically define the HGRS1987 and they are forming its connection to a global reference frame.

Thus, if we know the associated transformation parameters between the modern terrestrial reference frames and the 3D-velocities of a number of stations, we can "travel back to the past" in order to rebuild and thus validate the HGRS1987. This is the "essence" of this paper. By using ninety (90) stations located all over the country (derived from the official ITRS and ETRS89 solutions and dissertations, as well), we reconstructed the HGRS1987 as it is dictated by the 
geodetic-related methodologies. Our results are directly compared with the officially accepted transformation model.

\section{Methodology}

Our aim is to compare two different HGRS 1987 realizations:

- The first one is based on the reconstruction of the HGRS1987, following a rigorous geodetic procedure. The HGRS1987 will be obtained through various transformations. Our scope is to use the coordinates and the velocities in order to rebuild the HGRS1987 in a way that resembles its initial realization strategy. We shall call it the 'rigorous approach'.

- The second one refers to the official transformation model which its input is the 3DETRS89 coordinates. The local realization of ETRS89 in Greece is the Hellenic Terrestrial Reference of 2007 (HTRS07). The HTRS07 is aligned to the European Terrestrial Reference Frame of 2005 (ETRF2005) at the epoch of 2007.5. From now on, this latter approach will be called the 'officially accepted'. The HTRS07 is transformed to HGRS1987 through a methodology described by Katsambalos et al. (2010). The final output is the projection coordinates with respect to the HGRS1987. We remind that the projection of the HGRS1987 is the Transverse Mercator (one zone, longitude amplitude of 9 degrees) and the associated spheroid is the GRS80, respectively. The use of the projection coordinates was bounden since the official state's benchmarks coordinates refer only to the Transverse Mercator (or to the associated curvilinear coordinates). For longitude amplitudes less than 12 degrees, the Transverse Mercator projection does not present significant distortions, thus it is equivalent to use the projection instead the curvilinear coordinates.

\subsection{The rigorous realization of HGRS1987}

The rigorous reconstruction of HGRS1987 will be achieved by the following approaches:

1. Collection of data of the available stations which referred to one or more of the well-known reference frame (ITRF, ETRF). The data includes 3D coordinates and necessarily the 3D velocities.

2. Station transformation (i.e. of their coordinates and velocities, as well) to the ITRF90. The transformation was performed by using the ITRS/ETRS89 transformation-tool (ETRF/ITRF Transfrmation-Tool online-software, http://www.epncb.oma.be/_productsservices/coord_trans/). The aforementioned tool uses the 14-paremeter Helmert-transformation for the coordinates and velocities, respectively (for more details regarding this kind of transformation, see e.g. Altamimi et al. 2002, Soler and Snay 2004). The transformation parameters (seven for the coordinates and seven for the velocities), between each terrestrial reference frame and the ITRF90, can be found in http://itrf.ign.fr/trans_para.php. The final products were the coordinates and the velocities of the stations (with respect to the ITRF90). All the stations were transformed to ITRF90, epoch 1987.5. We have chosen the ITRF90 because it is the only ITRF for which there are officially released transformation parameters between it and the BTS87 (Boucher and 
Altamimi 1993). The epoch of 1987.5 refers to the middle of the year of HGRS1987 was released. The latter choice is arbitrary. Since the HGRS1987 was realized as a mosaic of discrete observations-sets, it is almost impossible to determine the epoch of the realization.

3. From ITRF90, we obtain the BTS87 (Boucher and Altamimi 1989) coordinates at the epoch of 1987.5, through a seven-parameter similarity transformation. BTS87 did not involve any estimated velocities, so we implemented only the coordinate transformation. The seven Helmert-transformation parameters connecting the ITRF90 to BTS87 (from ITRF90 to BTS87, Boucher and Altamimi 1993, Table 4) are as follows:

$$
\left(\begin{array}{c}
T_{x} \\
T_{y} \\
T_{z} \\
D \\
R_{x} \\
R_{y} \\
R_{z}
\end{array}\right)^{I T R F 90 \rightarrow B T S 87} \quad=\left(\begin{array}{c}
-1.1 \mathrm{~cm} \\
-0.8 \mathrm{~cm} \\
-5.7 \mathrm{~cm} \\
6 \mathrm{ppb} \\
0.4 \mathrm{mas} \\
0.2 \text { mas } \\
0.3 \text { mas }
\end{array}\right)
$$

where: $T_{x}, T_{y}, T_{z}$ the translations with respect to each axis, $D:$ the differential scale factor and $R_{x}, R_{y}, R_{z}$ : the rotations about each axis, respectively. We should note that the BTS87 adopted the AM0-2 tectonic plate motion model (Minster and Jordan 1978) for the 3D velocities (Boucher and Alatmimi 1989). However, we chose not to exploit AM0-2 model due to the fact that is obsolete and does not reflect sufficiently the tectonic complexity of the Hellenic area.

4. Having the BTS87-wise coordinates and using the three translations (which act as constraints), the result is to compute the HGRS1987 coordinates. We have to underline here that the three translations (applied to the BTS87) practically define the HGRS87. These three translations were estimated by an optimization procedure which led to the minimization (in a Least Squares sense) of the deflections of the vertical and the geoidal undulations of the Hellenic area, as well (Hellenic Mapping and Cadastral Organization, 1987). For more details regarding the fitting of a geodetic reference frame to the gravity related quantities, see Heiskanen and Moritz (1967) and Tscherning (1976). The relation of the BTS87 and HGRS1987 coordinates is defined (Hellenic Mapping and Cadastral Organization, 1987), pointwise:

$$
\left(\begin{array}{l}
X \\
Y \\
Z
\end{array}\right)_{i}^{B T S 87}=\left(\begin{array}{l}
X \\
Y \\
Z
\end{array}\right)_{i}^{H G R S 1987}+\left(\begin{array}{c}
-199.87 \\
74.79 \\
246.62
\end{array}\right) m
$$

5. The 3D-coordinates of HGRS are firstly converted to geodetic ones (longitude, latitude and geometric height) and finally, to projection coordinates.

3D-velocities play a crucial role in our analysis. By their use, there is an attempt to eliminate (as possible) the effect of the tectonic motion of the Hellenic area. Thus, the derived HGRS1987solution reconstructs the initial realization and the discrepancies mainly reflect the additional type of biases (observational and computational, respectively). 


\subsection{The officially accepted realization}

The officially accepted realization is managed through the official software of the Hellenic Cadastre and Cartographic Association. The 3D coordinates referred to HTRS07 are transformed to the projection coordinates. It is essential that the associated 3D-coordinates should be referred to the ETRF2005. Unfortunately, ETRF2005 is withdrawn and the transformation parameters, between the other contemporary reference frames and the ETRF2005, do not exist. By taking into account all the previous discussion, we formulate the following steps:

1. Same as the first step of the rigorous realization, described above.

2. The coordinates with respect to the various reference frames are transformed to the ETRF2000 (European Reference Frame of 2000, Boucher and Altamimi 2011) at epoch 2007.5, through the ITRS/ETRS89 transformation tool. We remind that the ETRF2000 is the last version of ETRS89.

3. Coordinates transformation from ETRF2000 to ETRF2005. The AUT1 station located at Thessaloniki (which belongs to the European Permanent Network-EPN) was the core station for HTRS07 realization (it was the only station that was fixed to ETRF2005 in order to define the reference frame of HTRS07). We estimated the 3D-translation between the ETRF2000 and ETRF2005 for this station, as follows:

$$
\delta \mathbf{x}_{A U T 1}=\mathbf{x}_{A U T 1}^{E T R F 2005(2007.5)}-\mathbf{x}_{A U T 1}^{E T R 2000(\mathbf{2 0 0 7 . 5 )}}=\left(\begin{array}{l}
12 \\
15 \\
14
\end{array}\right) \mathrm{mm}
$$

The translation vector $\delta \mathbf{x}_{\text {AUTI }}$ was added to all the stations in order to refer to ETRF2005, epoch 2007.5. The 3D-translation vector was estimated by using the 3D coordinate difference between the ETRF2005 and ETRF2000 in the core station (AUT1), respectively, and it should be considered in order to be consistent to the -withdrawn- ETRF2005 (the frame in which the HTRS07 is aligned).

4. The transformation of the HTRS07 coordinates to the projection coordinates of HGRS1987, by using the official software of the Hellenic Cadastre and Cartographic Association. This is carried out by a two-step procedure described in Katsambalos et al. 2010. Initially, a 7-parameter Helmert transformation between the HTRS07 and the HGRS1987 was made. The estimated Helmert parameters are given below (Katsambalos et al. 2010):

$$
\left(\begin{array}{c}
T_{x} \\
T_{y} \\
T_{z} \\
D \\
R_{x} \\
R_{y} \\
R_{z}
\end{array}\right)^{H T R S 07 \rightarrow H G R S 1987} \quad=\left(\begin{array}{c}
203.437 \mathrm{~m} \\
-73.461 \mathrm{~m} \\
-243.594 \mathrm{~m} \\
-0.294 \mathrm{ppm} \\
-0.170 \operatorname{arcsec} \\
-0.060 \operatorname{arcsec} \\
-0.151 \operatorname{arcsec}
\end{array}\right)
$$


Then, the transformation residuals (referring to the projection plane of the Transverse Mercator) were interpolated into a $2 \mathrm{~km} \mathrm{X} 2 \mathrm{~km}$ grid. The associated 2D rms of the residuals is $63 \mathrm{~cm}$. The official HTRS07 projection coordinates are computed as follows (pointwise):

$\left(\begin{array}{c}E \\ N\end{array}\right)_{i}^{H G R S 1987 / \text { official }}=\left(\begin{array}{c}\tilde{E} \\ \tilde{N}\end{array}\right)_{i}^{H G R S 1987}+\left(\begin{array}{c}\delta E \\ \delta N\end{array}\right)_{i}^{\text {grid }}$

where $\left(\begin{array}{c}E \\ N\end{array}\right)_{i}^{H G R S 1987-\text { official }}$ are the final official projection coordinates, $\left(\begin{array}{c}\tilde{E} \\ \tilde{N}\end{array}\right)_{i}^{H G R S 1987}$ are the initial coordinates (derived after the implementation of the 7-parameter Helmert transformation) and $\left(\begin{array}{l}\delta E \\ \delta N\end{array}\right)_{i}^{\text {grid }}$ are the gridded residuals which should be added (derived from interpolation). We should notice here that the official transformation model does not take into account any velocities.

Finally, the use of the projection coordinates differences between the rigorous and the officially accepted realization, give the sense of their consistency.

\section{Data}

Our data-set consists of 4 sources/cases of data:

1. From the official ITRF site: Eight (8) stations refer to ITRF2008 (epoch 2005.00).

2. From the EPN network: Six (6) stations refer to ITRF2008 (epoch 2005.00).

3. From the doctoral dissertation of Chatzinikos (2013): Sixty four (64) stations refer to ITRF2008 (epoch 2005.00).

4. From the CORS network of the National Observatory of Athens (NOA): Twelve (12) stations refer to ITRF2008 (variety of epochs).

Concerning the stations of the first case, we have six (6) old SLR mobile-stations and two (2) DORIS stations, referred to ITRF2008. For the cases (2), (3) and (4) the stations referred to continuously operating GNSS network and they are expressed to ETRF2000. The less accurate stations were the six old SLR mobile-stations. Nevertheless, we finally included all the stations since their standard deviations do not exceed the level of $5 \mathrm{~cm}$, which was considered sufficient for the present study. We call them 'external sites' since they were not involved in the realization of HTRS07. The associated velocities were estimated from time series analysis (for more details for the time series analysis one can see e.g. Nikolaidis 2002)

We should notice here that we had also about 20 benchmarks of the state's network, located at the northern part of the country, which were measured at least two times in different epochs. However, the quality of their spatial position and velocities was not ensured, thus we chose to exclude them from our analysis. The final number of the used stations is ninety (90). Figure 1 shows the horizontal velocities of the 90 stations (the velocities referred to ITRF90). 


\section{Results}

Table 1 summarizes the results of the two approaches (rigorous and 'officially accepted', as well). Figure 2 depicts the horizontal discrepancies, while Figure 3 shows the values of all horizontal discrepancies between these two approaches (official and the rigorous one, respectively).

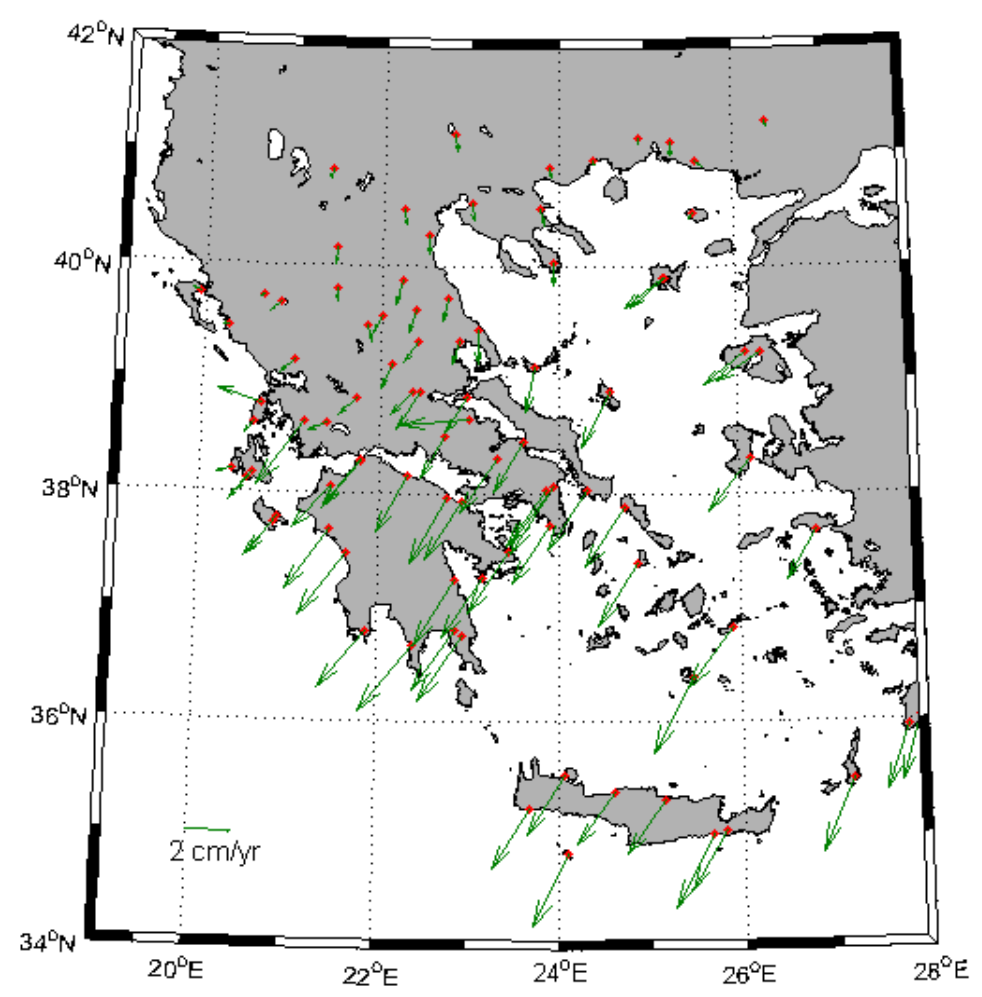

Figure 1 : The Greek stations (red circles) and their associated horizontal velocities (with respect to the ITRF90)

Table 1: The statistics of the discrepancies between the two approaches at the ninety stations. X and $\mathrm{Y}$ are the components of the projection coordinates, while $\delta \mathrm{r}$ is the horizontal discrepancy.

\begin{tabular}{cccc}
\multicolumn{4}{c}{ Units are in $[\mathrm{cm}]}$. \\
\hline min & -119.0 & -119.1 & $5 \mathrm{Y}$ \\
\hline $\max$ & 91.2 & 90.8 & 132.9 \\
mean & 17.2 & -12.5 & 51.4 \\
rms & 40.3 & 44.0 & 59.4 \\
\hline
\end{tabular}




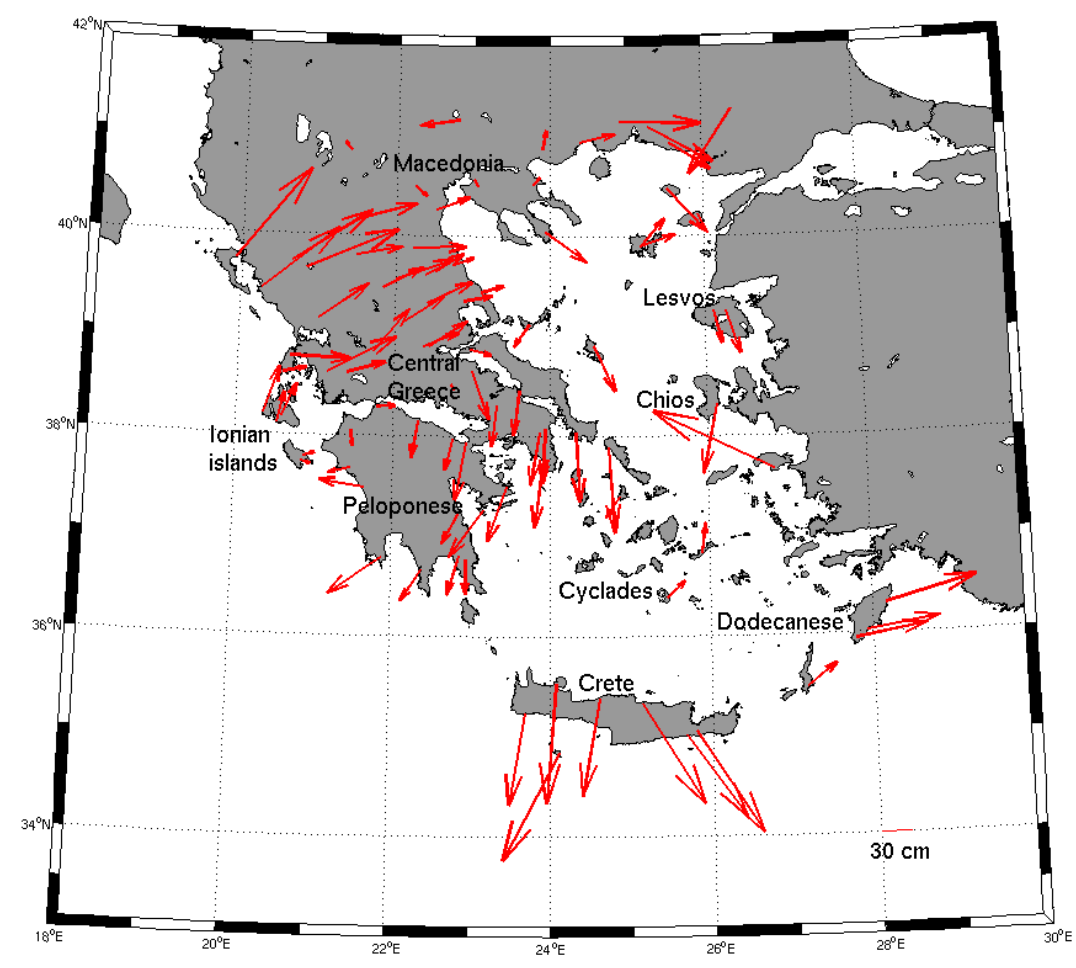

Figure 2: The horizontal discrepancies between the rigorous and the officially accepted approaches for HGRS 1987 coordinates estimation.

The results of our validation scheme show that the consistency between the rigorously derived HGRS 1987 and the official one is at the level of $60 \mathrm{~cm}$ for the total horizontal displacements. On the other hand, for the X and Y components, the consistency is at the levels of 40 and $44 \mathrm{~cm}$, respectively. The major difference occurs at Crete island $(132.9 \mathrm{~cm}$ horizontal difference), while at Thessaloniki (the Northern part of Greece) we detect the smallest one $(5.3 \mathrm{~cm})$. The visualization of the deformation vectors sets the sense of their inhomogeneity (e.g. major differences occurred at Crete and Central Greece). On the other hand, Macedonia and Northern Peloponnese show better consistency. The Eastern part of Greece (Dodecanese, Lesvos and Chios) illustrates also great inhomogeneous behavior. As a general comment, we can imply that by utilizing the new methodology, which reproduces the initial HGRS 1987, we have estimated a consistency between the two approaches at $59.4 \mathrm{~cm}$ (horizontal displacements). By using their own velocity model for Greece, Chatzinikos and Kotsakis (2016) have estimated the epoch of the minimum derived rms of the residuals, concerning the Helmert-transformation between HGRS1987 and the ITRF2008. They found that epoch 1969.00 shows the minimum rms of the residuals $(45 \mathrm{~cm})$ which is close to our results.

The mean average of the horizontal discrepancies lays at $51.4 \mathrm{~cm}$, confirming the existence of various systematic effects. In addition, as we mentioned before, the observed inconsistencies are closely related to the fact that the HGRS1987 was realized by observation sets measured at different (and unknown) epochs. Moreover, it reflects existing biases from the classical type observations and the satellite techniques of mid-eighties. Additionally, it is possible that the observed inconsistencies reflect the inhomogeneous velocity field of the Hellenic area (Figure 1). It is well-known that the Southern part of the country and the Aegean islands show a significant south-south east motion with respect to the Eurasian plate (see e.g. Kahle et al. 1998 Hollenstein 
et al. 2008, Chatzinikos 2013). Hence, the inhomogeneous tectonic motion of the area could distort the accuracy of the HGRS1987.

However, the aforementioned inhomegeneity of the velocity field does not agree with the situation regarding the biases (see Figure 2). This is an indication that the nature of the biases can be not easily defined and the most rational evaluation/interpretation strengthens and supports the claim that mainly are due the influence of various systematic effects (e.g. problematic measurements, problematic network orientation and the tectonic motion) which have 'contaminated' the HGRS1987 final solution.

\section{Summary and Future work}

In this paper, we presented a rigorous approach of reconstructing the HGRS1987, by using geodetic tools as the Helmert-transformation, both for coordinates and velocities. We compare the rigorously derived solution to the officially accepted (from the Greek state) solution and we found a consistency at the level of $60 \mathrm{~cm}$. Additionally, we estimated their relative systematic differences, revealing a bias of $51.4 \mathrm{~cm}$ nationwide. The bias amount indicates various systematic effects which significantly distort the HGRS1987.

By taking into consideration the severe distortion of the HGRS1987, the official transformation scheme for HGRS1987 performs sufficient accuracy $(8.3 \mathrm{~cm})$. We should underline here that, due to the intense geophysical behaviour of the Hellenic area, the HGRS1987 realization through the HTRS07 must be constantly monitored from the states agencies. Otherwise, the quality of the HGRS1987 will be inevitably reduced rigorous approach can also apply to many of the old geodetic reference frames which were realized by 'classical' observations.

\section{ACKNOWLEDGEMENTS}

Dr. C. Bruyninx and Dr. A. Keneyres are kindly acknowledged for providing the velocities of two EPN stations (www.epncb.oma.be). We kindly acknowledge the National Observatory of Athens (NOA), for publicly providing data of its CORS GNSS network. Dipl. Ing. Nikolaos Demirtzoglou, Dr. Ing. Grigorios Tsinidis and Dipl. Ing. Georgios Rigopoulos kindly offered the coordinates of totally twenty state's network benchmarks. Dr. Victor Cazcarra Bes helped us with the Spanish translation. The anonymous reviewers are kindly acknowledged for their efforts to improve the initial manuscript.

\section{REFERENCES}

Altamimi, Z., P. Sillard, and C. Boucher 2002. ITRF2000: A new release of the International Terrestrial Reference Frame for Earth science applications. Journal Geophys. Res., vol. 107, No.B10, 2214, pp. 19 DOI:10.1029/2001JB000561.

Boucher, C. and Altamimi, Z. 1989. The initial IERS Terrestrial Reference Frame. (IERS Technical Note ; 1). Paris: Central Bureau of IERS - Observatoire de Paris, 1989. iv, 98 p. 
Boucher, C. and Altamimi Z., 1993. Development of a conventional reference system. In D. E. Smith and D. L. Turcotte, eds. Contributions of space geodesy to geodynamics: technology, geodynamics series. Washington, DC: American Geophysical Union. Vol. 25.

Boucher, C. and Altamimi Z., 2011. Memo: specifications for reference frame fixing in the analysis of a EUREF GNSS campaign. Available at: 〈http://etrs89.ensg.ign.fr/memo-V8.pdf> [Accessed: 10 February 2015].

Chatzinikos, M., 2013. Study of the earth's crust displacements in the area of Greece analyzing GNSS data. PhD Thesis, Dept. of Rural and Surveying Engineering, Aristotle University of Thessaloniki, Greece (in Greek).

Chatzinikos, M. and Kotsakis, C., 2016. Appraisal of the Hellenic Geodetic Reference System 1987 based on backward-transformed ITRF coordinates using a national velocity model. Survey Review (accepted article). DOI: http://dx.doi.org/10.1080/00396265.2016.1180797.

EUREF Permanent GNSS Network (EPN). ETRF/ITRF Transformation[online]. Available at: <http://www.epncb.oma.be/_productsservices/coord_trans> [Accessed: 15 February 2015].

Heiskanen, W. and H. Moritz, 1967. Physical Geodesy. W.H Freeman and Company, San Francisco, USA.

Hellenic Mapping and Cadastral Organization, 1987. The Hellenic Geodetic Reference System 1987. Report, Ministry of Environment, Urban Planning and Public Works (in Greek).

Hollenstein, C., M.D. Müller, A. Geiger and H.G. Kahle, 2008. Crustal motion and deformation in Greece from a decade of GPS measurements, 1993-2003. Tectonophysics, vol. 449, pp. 17-40.

International Terrestrial Reference Frame (ITRF). Transformation parameters [online]. Available at: <http://itrf.ign.fr/trans_para.php> [Accessed: 18 March 2015].

Kahle, H.G., C. Straub, R. Reilinger, S. McClusky, R. King, K. Hurst, G. Veis, K. Kastens and K. P. Cross, 1998. The strain rate field in the eastern Mediterranean region, estimated by repeated GPS measurements. Tectonophysics, vol. 294, pp. 237-252.

Katsambalos, K., Kotsakis, C. and Gianniou, M., 2010. Hellenic terrestrial reference system 2007 (HTRS07): a regional realization of ETRS89 over Greece in support of HEPOS. Bulletin of Geodesy and Geomatics, LXIX(2-3), pp.151-64.

Minster, J. B. and T.H. Jordan, 1978. Present-day Plate Motions. J. Geophys. Res, 80, pp. 244248.Nikolaidis, R., 2002. Observation of Geodetic and Seismic Deformation with Global Positioning System. PhD thesis, University of California, pp.249.

Rokos, D., K. Kyriazis and P. Lolonis, 2010. Setting Up the Infrastructure for Improving the Development of Cadastre en Greece. FIG Congress 2010, Sydney, Australia.

Soler, T. and Snay, R., 2004. Transforming Positions and Velocities between the International Terrestrial Reference Frame of 2000 and North American Datum of 1983. Journal of Surveying Engineering, Vol. 130, No. 2.

Takos I., 1989. New adjustment of Greek geodetic networks. Journal of the Hellenic Military Geographic Service, Issue No. 36, pp.15-30 (in Greek).

Tscherning, C.C., 1976. Determination of datum-shift parameters using least squares collocation. Bollettino di Geodesia e Scienze Affini 01/1976; XXXV(2):173-183.

Veis G., 1996. National report of Greece. Report on the Symp. of the IAG Sub-commission for the European Reference Frame (EUREF), Ankara, 22-25 May 1996. Report, Verlag der Bayerischen Akademie der Wissenschaften, Heft Nr. 57. 
Received in 2016, August $11^{\text {th }}$.

Accepted in 2017, January $11^{\text {th }}$. 